\title{
46. Storing Information on Disk (continued)
}

Generally, a file will contain a large number of records - e.g. one record for each type of stock on the shelves.

So, the program has to open the file, deal with the records one at a time (for each one, getting the data and writing the record to the file before moving on to the record for the next item) and finally close the file.

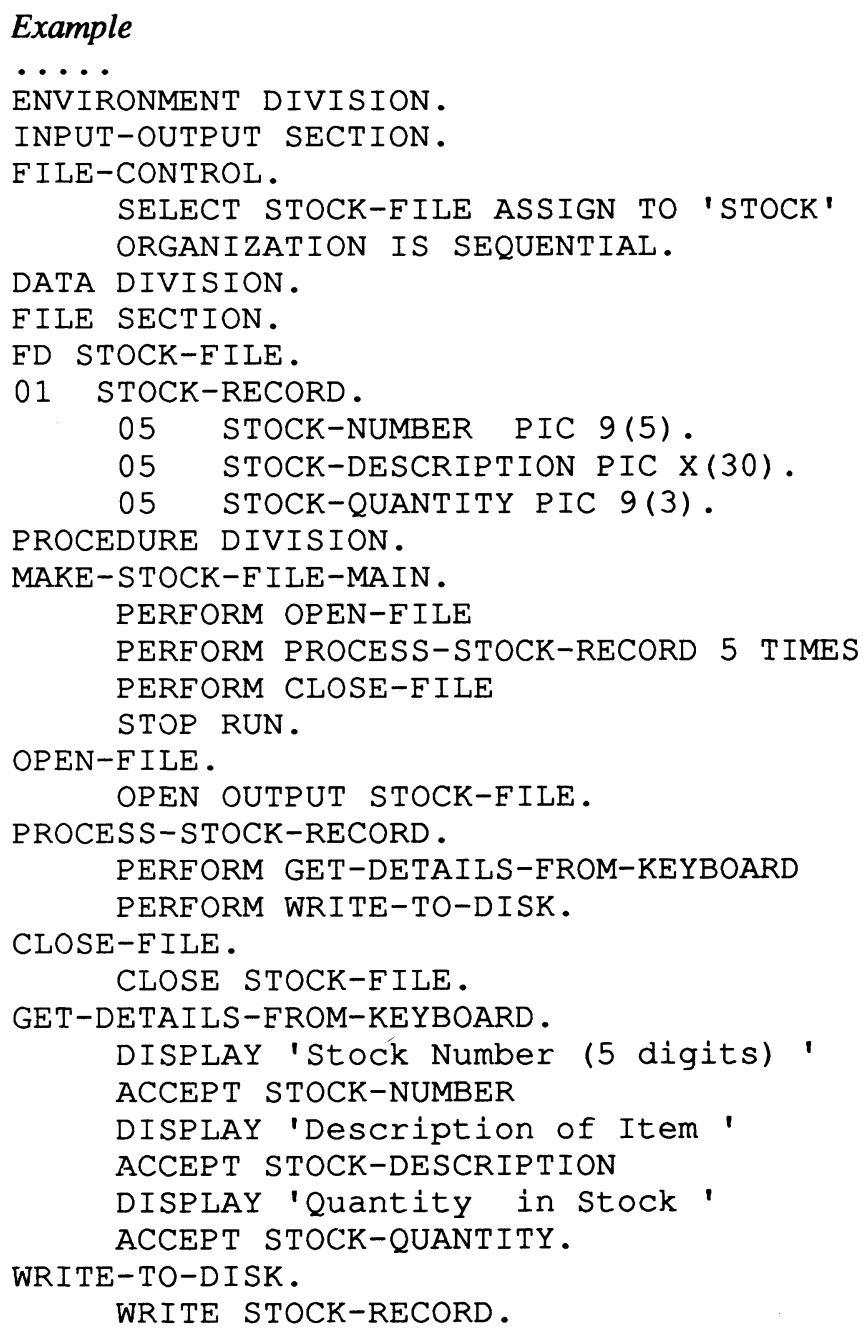

1. Write a program which will ask for the name (20 letters), and mark (3 digits) for each student in a class of twenty and save the records to disk.

2. Write a program which will ask for the name and wage for each of five employees and save them on disk. 